\section{Treatment of phenprocoumon intoxication with cholestyramine}

Cholestyramine enhances the elimination of phenprocoumon (Marcoumar) in man by interrupting its enterohepatic recycling.' Recently we saw a patient early after an intoxication with phenprocoumon and followed the plasma concentration of the drug before and after cholestyramine treatment. We found that its elimination from the body can be greatly enhanced by giving cholestyramine by mouth.

\section{Case report}

A 35-year-old man, treated with phenprocoumon for one year because of thromboangiitis obliterans, needed an average of $3 \mathrm{mg}$ daily to maintain a therapeutic level (prothrombin complex activity of between 15 and $30 \%$ of normal). He stated that between midnight and 4 am the previous night he had swallowed 30 to $353-\mathrm{mg}$ tablets of phenprocoumon and about 20 tablets of Trivastal (each containing $20 \mathrm{mg}$ 2-(4-piperonyl-piperazin-1-yl)-pyrimidin), intending to commit suicide. We saw the man at noon the next day. We gave him Vitamin $K_{1}$ and a commercially available prothrombin complex concentrate (PPSB human, DRK-Blutspendedienst) immediately after prothrombin testing and maintained him on this therapy so long as the prothrombin complex activity was below the therapeutic range. The prothrombin time was determined in a clinical service laboratory, and the plasma concentration of phenprocoumon was measured over a period of 17 days by a fluorometric method (figure). ${ }^{2}$ The first measurement of $46 \mu \mathrm{mol} / 1(13 \mu \mathrm{g} / \mathrm{ml}) 14$ to 18 hours after taking the drug confirmed that a large dose of phenprocoumon had been taken. The concentration of $46 \mu \mathrm{mol} / 1$ was partly due to the regular anticoagulant therapy but mostly to the additional 30 to 35 tablets. After a short distribution phase the plasma concentration gradually decreased monoexponentially, the half life being 6.8 days. After seven days, when the plasma concentration had declined to about $20 \mu \mathrm{mol} / 1(5.5 \mu \mathrm{g} / \mathrm{ml})$ (above the therapeutic level), cholestyramine $4 \mathrm{~g}$ was given three times daily for 10 days. During this period the phenprocoumon plasma concentration declined with a half life of 3.5 days.

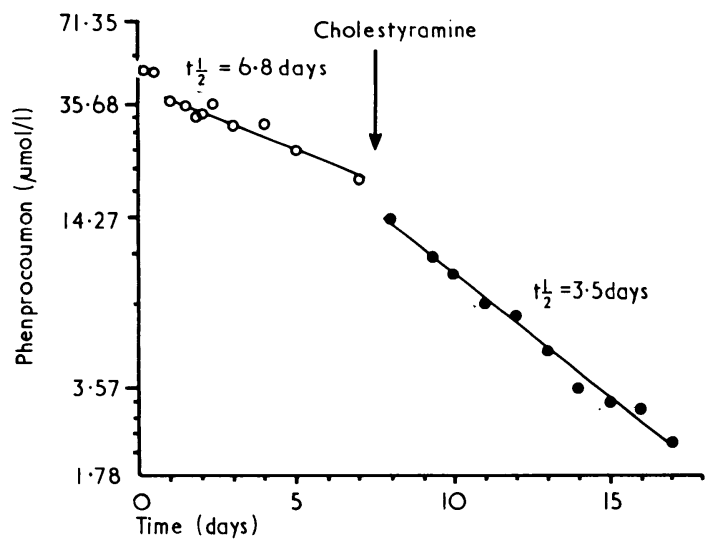

Phenprocoumon plasma concentrations after ingestion of 90-105 mg before ( $t \frac{1}{2}=6.8$ days) and during treatment with cholestyramine ( $t \frac{1}{2}=3.5$ days). Time zero indicates time of admission.

Conversion: SI to traditional units: Phenprocoumon: $1 \mu \mathrm{mol} / 1 \approx 0.28 \mu \mathrm{g} / \mathrm{ml}$.

\section{Comment}

The clinical findings and the plasma concentrations suggest that most of the dose of 30-35 tablets of phenprocoumon had been absorbed. The half-life of phenprocoumon in the postabsorptive phase corresponds to those previously reported..$^{1-3}$ This may indicate that the rate of elimination of phenprocoumon was not greatly affected by the Trivastal taken with it and that there is no capacitylimited elimination of phenprocoumon. The latter has been confirmed by others. When cholestyramine was given in doses of $12 \mathrm{~g} /$ day by mouth the elimination rate of phenprocoumon was nearly doubled. This accords with results obtained in healthy volunteers after intravenous administration of phenprocoumon.

The use of cholestyramine in phenprocoumon overdosage and intoxication is recommended because it reduces the gastrointestinal absorption of phenprocoumon in $\operatorname{man}^{5}$ and it enhances the elimination of phenprocoumon by interrupting its enterohepatic recycling. Since cholestyramine also enhances the elimination of warfarin in healthy people the same therapeutic principle may also apply with that drug.

We thank Mrs Ulrike Bolz for expert technical help. The study was supported by a grant from the Deutsche Forschungsgemeinschaft.

1 Meinertz, T, et al, Clinical Pharmacology and Therapeutics, 1977, 21, 731. 2 Jähnchen, E, et al, Clinical Pharmacology and Therapeutics, 1976, 20, 342. ${ }^{3}$ Heni, N, and Glogner, P, Naunyn-Schmiedeberg's Archives of Pharmacology, 1976, 293, 183.

${ }^{4}$ Seiler, K, and Duckert, F, Thrombosis et Diathesis Haemorrhagica, 1969, 21, 320.

${ }^{5}$ Hahn, K J, et al, European fournal of Clinical Pharmacology, 1972, 4, 142.

(Accepted 6 April 1977)

Zweite Medizinische Klinik, Universität Mainz, D-6500 Mainz, Germany

THOMAS MEINERTZ, MD, research fellow

HANS-JOACHIM GILFRICH, MD, professor of internal medicine

RENATE BORK, MD, research fellow

Pharmakologisches Institut der Universität Mainz, D-6500 Mainz, Germany

EBERHARD JÄHNCHEN, MD, professor of pharmacology

\section{4-Hour ambulatory electrocardiographic monitoring on a regional basis}

Twenty-four hour ambulatory electrocardiographic (ECG) monitoring is an established technique in the assessment of patients suspected of transient cardiac arrhythmias. ${ }^{1-3}$ Suitable recording equipment is relatively cheap, but since a commercial reporting service for 24-hour ECG recordings is lacking in Britain, the technique has been available only to centres that can afford the expensive equipment needed to process the records.

In establishing a 24-hour ECG monitoring service for the Birmingham Region we tried to cover as wide a geographic area as possible by using district general hospitals as satellite recording stations, and by sending records to a central analysis unit.

\section{Methods and results}

Recordings were accepted from physicians practising in 10 centres throughout the Midlands and one centre in East Anglia. Recordings were made by ECG technicians at the hospital concerned and were posted to the analysis unit.

Equipment-Recordings were made on standard C120 magnetic tape cassettes $^{4}$ using a miniature tape recorder (Oxford Electronic Instrument Company). Tape recordings were analysed with a commercially available automatic replay and analysis system (The Oxford Electronic Instrument Company) based on that originally described by Cashman. ${ }^{5}$ The analyser provided 10-second samples of any arrhythmias detected, written out by a

Arrhythmias detected in 124 patients with use of 24-hour ambulatory ECG monitoring service. Figures are numbers (\%) of patients

\begin{tabular}{|c|c|c|}
\hline \multirow[b]{2}{*}{ Arrhythmia detected } & \multicolumn{2}{|c|}{ Clinical presentation } \\
\hline & $\begin{array}{c}\text { Possible } \\
\text { Adams-Stokes disease }\end{array}$ & $\begin{array}{c}\text { Palpitations } \\
\text { and other symptoms }\end{array}$ \\
\hline 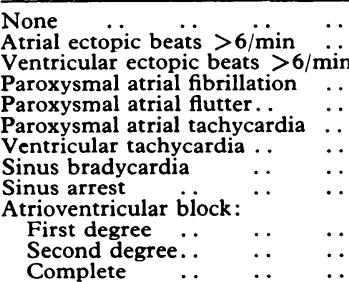 & $\begin{array}{l}25(39) \\
3(4 \cdot 7) \\
13(20 \cdot 3) \\
6(9 \cdot 4) \\
1(1 \cdot 6) \\
3(4 \cdot 7) \\
4(6 \cdot 25) \\
5(7 \cdot 8) \\
8(12 \cdot 5) \\
2(3 \cdot 1) \\
2(3 \cdot 1) \\
5(7 \cdot 8)\end{array}$ & $\begin{array}{c}28(46 \cdot 6) \\
10(16 \cdot 6) \\
15(25 \cdot 0) \\
5(8 \cdot 3) \\
4(6 \cdot 6) \\
1(1 \cdot 6) \\
4(6 \cdot 6) \\
2(3 \cdot 3)\end{array}$ \\
\hline
\end{tabular}


standard electrocardiograph. These samples, together with a report, were returned to the referring clinician.

Of the first 139 patients monitored, 15 records were unsuitable for analysis because of poor recording technique. The 124 patients successfully monitored all had symptoms suggestive of transient cardiac arrhythmias. These symptoms had not been identified by the referring clinician using conventional techniques. The patients were divided into two clinical groups. The first group comprised 64 patients with symptoms characterised by disturbances of consciousness, which were suggestive of Adams-Stokes attacks. The second group was composed of 60 patients with palpitations or other symptoms not including disturbances of consciousness.

The results are shown in the table. The incidence of serious arrhythmias requiring urgent therapeutic intervention was higher in the group of patients with more serious symptoms.

\section{Comment}

We found it possible to establish a viable 24-hour ECG monitoring service on a regional basis. No increase in medical or technical manpower was required, and the running costs were low-C120 cassettes are available to bulk purchasers at 75 p or less. In providing a simple diagnostic service, we could keep the cost of equipment to a minimum by using a relatively unsophisticated analyser.

We had initially feared that recording techniques would be inadequate in peripheral hospitals performing sporadic investigations. These fears were proved groundless. Technical problems occurred with the portable recorders, as they were rather fragile. Nevertheless, technically unsatisfactory records were rare.

Initially the service has been both diagnostically efficient and technically satisfactory. In the current economic climate we suggest that this method may have much to recommend it.

1 Curry, P V L, in Cardiac Arrhythmias, The Modern Electro-physiological Approach, ed D M Kricker and J F Goodwin. London, W B Sanders. 2 Bleifer, S B, et al, Progress in Cardiovascular Disease, 1974, 16, 569.

3 Crook, B R M, et al, British Heart fournal, 1973, 35, 1009.

${ }^{4}$ Littler, W A, et al, British Medical fournal, 1972, 3, 76.

5 Cashman, P M, and Stott, F D, Biomedical Engineering, 1974, 9, 54.

(Accepted 20 April 1977)

Department of Cardiology, Queen Eliazbeth Hospital, Birmingham B15 2TH

P J CADIGAN, MRCP, senior registrar in cardiology (present appointment: senior registrar, The General Hospital, Birmingham B4 $6 \mathrm{NH}$ )

D O WILLIAMS, MB, MRCP, honorary senior registrar (present appointment: consultant cardiologist, Newcastle General Hospital, Newcastle upon Tyne NE4 6BE)

\section{Bilateral atrial myxomas diagnosed preoperatively and successfully removed}

Primary cardiac tumours are rare. Most are atrial myxomas, and about $75 \%$ of these arise in left atrium. ${ }^{1}$ Diagnosis may be difficult and used often to be made at necropsy. ${ }^{2}$ With improved diagnostic and surgical techniques these tumours have a good prognosis. We report the third successful preoperative diagnosis and removal of biatrial myxomas. ${ }^{3}$

\section{Case report}

A 21-year-old woman presented in April 1973 with a history of headaches, depression, leg pains for six months, and a weight loss of $10 \mathrm{~kg}$. Clinical examination was normal and the only abnormal laboratory findings were a haemoglobin of $11.4 \mathrm{~g} / \mathrm{dl}$ and an ESR of $90 \mathrm{~mm}$ in $1 \mathrm{~h}$. Her symptoms improved. Her second child was delivered in March 1974 with no obstetric or medical complications. During pregnancy her ESR fell to $33 \mathrm{~mm}$ in $1 \mathrm{~h}$. Ten weeks post partum she complained of transient maculopapular rashes of both hands and feet. In January 1975 she was admitted with breathlessness on exertion, faintness, and excessive perspiration.

Clinical examination was normal. Abnormal laboratory results were: haemoglobin $10 \mathrm{~g} / \mathrm{dl}$, ESR $134 \mathrm{~mm}$ in $1 \mathrm{~h}$, serum iron $3.6 \mu \mathrm{mol} / 1(20 \mu \mathrm{g} /$ $100 \mathrm{ml}$ ) (normal $9-32 \mu \mathrm{mol} / 1(50-80 \mu \mathrm{g} / 100 \mathrm{ml})$ ), iron binding capacity $45 \mu \mathrm{mol} / 1 \quad(250 \mu \mathrm{g} / 100 \mathrm{ml})$ (normal $45-75 \mu \mathrm{mol} / 1 \quad(250-420 \mu \mathrm{g} / 100 \mathrm{ml})$ ), alkaline phosphatase $129 \mathrm{KAU} / 1$ (normal 28-100). Shortly after admission she had a pulmonary embolism and was given anticoagulants. During the next four months she became increasingly breathless, had frequent haemoptyses, and complained of dizziness, anorexia, and weight loss. She was breathless at rest and auscultation revealed a fourth heart sound, a loud first sound with a loud opening snap, and a systolic murmur, all maximal at the apex and not varying in intensity with position. Biatrial myxomas were diagnosed and a reversion of the heart sounds to normal and the development of a tricuspid systolic murmur were in keeping with the diagnosis.

Echocardiography showed a left atrial myxoma (figure). Angiocardiography showed poor filling of the left lower lobe pulmonary artery but was unable to define the left atrial myxoma. Surgery disclosed a gelatinous right atrial myxoma attached to the septum by a small stalk and prolapsing into the right ventricle. This myxoma was removed and an incision into the posterior part of the septum revealed a left atrial myxoma adherent to the septum by a small stalk opposite the site of origin of the right myxoma. Both consisted of polypoid masses of mucoid material covered by a single layer of endothelium. Nowhere did the appearance suggest a transition from thrombus to myxoma and none of the stroma cells had features suggestive of malignancy.

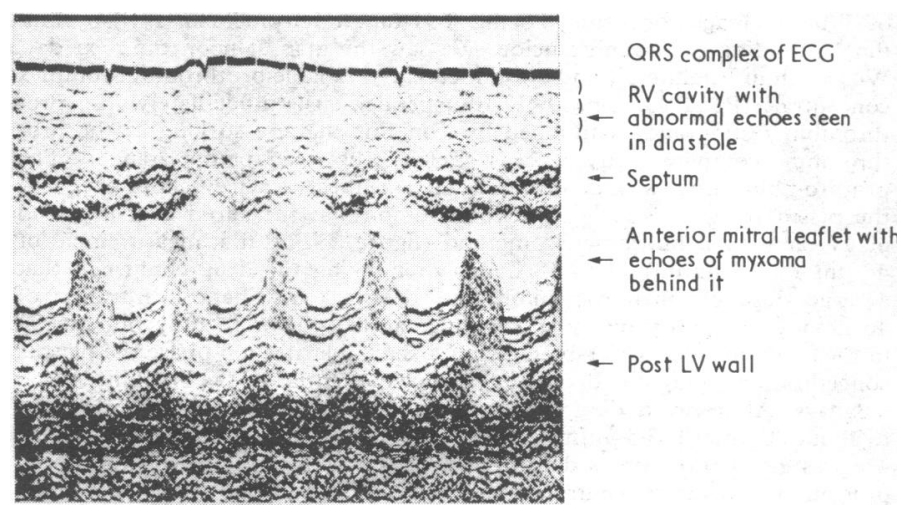

Echocardiogram showing presence of left atrial myxoma and abnormal echoes in right ventricle.

\section{Comment}

Eighteen cases of synchronous biatrial myxomas have been reported. Over $60 \%$ died before, during, or shortly after surgery. Awareness of the diagnosis and improved diagnostic and surgical techniques have resulted in a better prognosis for these tumours. Dyspnoea on exertion and peripheral emboli occur in over $50 \%$ of cases; syncope, dizziness, palpitations, and joint or muscle pains in $30 \%$; and pulmonary emboli and oedema in $20 \%$. Postural symptoms are infrequent. Angiocardiography in patients with a low cardiac output may not give enough contrast in the left atrium to outline the tumour and also has the danger of embolisation. Echocardiography is noninvasive, avoids this complication, and, we hope, will supersede angiocardiography when atrial myxoma is suspected.

1 Fletcher, F W, fournal of the Iowa State Medical Society, 1963, 53, 545.

2 Nichols, J, and Hennigar, G, Archives of Pathology, 1959, 67, 24.

${ }^{3}$ Kawashima, Y, et al, fournal of fapanese Association of Thoracic Surgeons, 1973, 21, 812.

4 Zatchuk, R, et al, fournal of Thoracic and Cardiovascular Surgery, 1975, 69, 291.

(Accepted 6 April 1977)

MRC Division of Communicable Diseases, Clinical Research Centre, Harrow

K G NICHOLSON, MB, MRCP, scientific staff

Department of Thoracic Surgery, Royal Infirmary, Sheffield

A L PRIOR, MB, FRCS, registrar

A G NORMAN, MCHIR, FRCS, consultant thoracic surgeon

Northern General Hospital, Sheffield

D R NAIK, MB, FRCR, consultant radiologist

A KENNEDY, MD, MRCPATH, consultant histopathologist

Department of Medicine, Royal Hospital, West Street, Sheffield R V HAGI'E, MB, MRCP, senior registrar

D R CULLEN, MD, MRCP, consultant physician 